Пространственная Экономика

2008. № 3. C. 45-62

А. Г. Исаев

\title{
ПРОБАЕМЫ ПОВЫШЕНИЯ
}

ТЕХНОЛОГИЧЕСКОГО УРОВНЯ

ПРОМЫШАЕННОГО КОМПАЕКСА

ХАБАРОВСКОГО КРАЯ

\begin{abstract}
Рассматриваются препятствия технологического характера, затрудняющие выведение экономики Хабаровского края на траекторию устойчивого роста. Предлагаются некоторые принципиальные схемы решения имеющихся проблем. Показывается, что наиболее приемлемый способ заключается в использовании научно-технического потенциала присутствующей в регионе авиационной промышленности.
\end{abstract}

Технологический уклад, теория многоуровневой экономики, региональное развитие, авиационная промышленность, Хабаровский край.

\section{1. ВВЕДЕНИЕ}

За время, прошедшее с момента стабилизации экономики страны в конце 1990-х гг., как на региональном, так и на федеральном уровнях звучат призывы к смене стратегии развития восточных районов России, базирующейся на эксплуатации их природных ресурсов, и переходу к более технологичным вариантам развития, предполагающим изменение структуры экономики в пользу производств с высокой долей добавленной стоимости. С этой точки зрения Хабаровский край представляет определенный интерес, поскольку создававшийся на протяжении XX в. комплекс производств на его территории составляет основу обрабатывающей промышленности всего

(С) Исаев А. Г., 2008

Работа выполнена при поддержке интеграционного проекта ДВО и СО РАН № 06-II-CO-10-038. 
Дальнего Востока. За годы советской власти в крае были созданы достаточно масштабный машиностроительный комплекс, металлургическое производство, основной целью создания которого было обеспечение обрабатывающих производств региона конструкционными материалами, а также два крупных нефтеперерабатывающих предприятия. Однако общеизвестным фактом является то, что главная отрасль, создающая добавленную стоимость, машиностроительное производство, с начала периода рыночных реформ и по настоящее время продолжает находиться в депрессивном состоянии. Как следствие, на протяжении 1990-х гг. региональной промышленности приходилось развиваться с опорой лишь на собственные богатые природные ресурсы. Попытки региональных властей изменить ситуацию, а именно, перейти от сырьевой специализации региона к специализации на продукции с высокой долей добавленной стоимости, как это было до осуществления рыночных реформ, не приводят к серьезным результатам.

Рост объемов продукции машиностроения, начавшийся с 2000 г., вполне можно назвать существенным в сравнении с депрессивными 1990-ми гг. ${ }^{1}$ Однако этот подъем был связан в большей степени с внеэкономическими факторами. ОАО «Комсомольское-на-Амуре авиационное производственное объединение им. Ю. Гагарина» (КнААПО), крупнейшее на Дальнем Востоке предприятие оборонного машиностроения ${ }^{2}$, практически после десятилетия бездействия получило государственный оборонный заказ на производство военной техники. Учитывая высокий технологический уровень предприятия (в особенности на фоне основной массы предприятий обрабатывающего сектора), его относительно узкую специализацию, а также высокую стоимость единицы выпускаемой продукции, неудивительно, что одно-единственное предприятие столь существенно изменило сложившуюся в последнее десятилетие $\mathrm{XX}$ в. картину промышленного развития Хабаровского края. Отсутствие нового оборонного заказа вновь привело к снижению загрузки производственных мощностей предприятия в 2004 г., вследствие чего объем выпуска в машиностроительной отрасли края по отношению к 2003 г. уменьшился почти на $25 \%$.

Столь значительные воздействия, которые оказывает на экономику региона лишь один высокотехнологичный, но узкоспециализированный экономический агент, при наличии относительно большой массы крупных промышленных предприятий машиностроения, вносящих по каким-то причинам лишь незначительный вклад в общее развитие промышленного комп-

${ }^{1}$ В 2003 г. по сравнению с 1997 г. выпуск увеличился в 3,5 раза. Если в 1997 г. доля продукции машиностроения в общем выпуске промышленной продукции Хабаровского края составляла $19,2 \%$, то в 2003 г. она повысилась до $39,7 \%$.

2 Специализирующееся на выпуске боевых самолетов-истребителей марки «Су». 
лекса, побуждает исследовать эти причины, вероятные угрозы, которые они содержат для экономики региона, а также возможные пути решения имеющихся проблем, могущих в перспективе нанести серьезный вред и без того неустойчиво функционирующей обрабатывающей промышленности территории. Предметом анализа в настоящей статье является технологический уровень промышленных предприятий Хабаровского края, а также технологический уровень промышленного комплекса региона, как средний уровень технологий совокупности промышленных экономических агентов. В разделе 2 приводится общая характеристика теорий технологических укладов и многоуровневой экономики. Раздел 3 посвящен анализу промышленного комплекса Хабаровского края с позиций вышеуказанных теорий. Наконец, в разделе 4 представлены варианты повышения общего технологического уровня экономики региона.

\section{2. ТЕОРИИ ИНДУСТРИАЛЬНО-ТЕХНОЛОГИЧЕСКОГО РАЗВИТИЯ}

Общепризнанным является тот факт, что благодаря научно-техническому прогрессу экономический рост в промышленно развитых странах превратился в устойчивую тенденцию. Результатом НТП в этих странах является наличие наукоемких производств, создающих продукцию с высокой долей добавленной стоимости и выступающих в качестве «локомотива» роста экономики.

С точки зрения теории больших циклов конъюнктуры мирового хозяйства развитие представляет собой процесс смены технологических укладов. Н. Д. Кондратьев основой больших циклов видел процессы радикального обновления производительных сил общества, технологические перевороты, движимые значительными техническими изобретениями, внедрение которых в хозяйственную жизнь требует определенных экономических условий. Под массовым замещением устаревших производительных сил в современной экономической литературе подразумевается смена технологических укладов. Технологический уклад - это совокупность подразделений, близких по качественным характеристикам используемых технологий и выпускаемой продукции [1, с. 22].

Теорию больших циклов Н. Д. Кондратьева, таким образом, можно представить как теорию эволюции технологических укладов. С учетом отмеченных Кондратьевым трех больших циклов (смен трех технологических укладов), до конца XX в. сменилось пять укладов, и первая четверть XXI в. время наступления шестого, технологического уклада [4, с. 719]. Зарождение нового технологического уклада происходит, когда в экономической структу- 
ре еще доминирует предшествующий [2]. По мере достижения прежним укладом своего предела роста начинается перераспределение ресурсов в пользу капитала, относящегося к последующему укладу. Новый уклад затем становится основой экономического роста и занимает доминирующее положение в структуре производства товаров и услуг. Период жизни очередного технологического уклада заканчивается вместе с исчерпанием резервов повышения технологически значимого результата ${ }^{1}$, который может быть достигнут с применением заданной технологии. Другими словами, это происходит по мере достижения технологического предела. Последний является количественным ограничением возможностей применяемых технологий, для преодоления которого необходимо внедрение более совершенных технических средств. Технологический уклад можно описать с помощью S-образной логистической кривой, которая отражает три этапа в его развитии. Эффект от капитальных вложений будет повышаться не линейно, а в зависимости от того, в какой фазе жизненного цикла находится уклад [7]. Последовательная смена технологических укладов не означает полного вытеснения одного другим. Одновременно в экономической системе может функционировать несколько технологических укладов. В этом случае между ними неизбежно происходит конкуренция за ограниченные ресурсы [1, с. 23].

Исследование проблем конкуренции за обладание ограниченными ресурсами в экономике командного типа и сформировавшихся в результате этого производственных контуров разного качественного уровня нашло отражение в работах академика Ю. В. Яременко. Исходным постулатом теории многоуровневой экономики (теории массовых и качественных ресурсов) является утверждение о том, что в экономике любого типа ресурсы, используемые в процессе воспроизводства, качественно неоднородны [15]. Для трудовых ресурсов под качественными характеристиками подразумевается различный уровень образования и квалификации, для оборудования, материалов и энергоносителей - совокупность их различных технических свойств. Среди ресурсов выделяются две большие группы - массовые и качественные. Первые из них - это ресурсы низкого и среднего уровня качества ${ }^{2}$. Именно они обеспечивали потребности быстрого экономического роста в СССР. С другой стороны, необходимость обеспечения высокого качества продукции в ряде отраслей обусловила концентрацию ограниченных качественных ресурсов в достаточно узком сегменте советской экономики [14]. Формирование

\footnotetext{
${ }^{1}$ Например, технологически значимым результатом в информатике является количество операций в единицу времени, в производстве стрелкового вооружения - дальность стрельбы при заданной точности и т. д. Имеющийся уровень технологий позволяет увеличивать этот результат лишь до определенных пределов. Выход за эти пределы возможен лишь с внедрением технологий следующего поколения.

${ }^{2}$ К массовым ресурсам также относятся топливно-энергетические ресурсы.
} 
системы приоритетов в распределении высококачественных ресурсов обусловило возникновение, по определению Ю. В. Яременко, многоуровневой экономики, сущностью которой является наличие хозяйственных уровней, функционирующих на разных технологических укладах и различающихся качеством используемых ресурсов.

Ввиду ограниченности качественных ресурсов последние распределялись между различными видами производства посредством системы приоритетов. Производственные подразделения, обладавшие определенными привилегиями ${ }^{1}$, имели значительное преимущество в использовании передовых технологических достижений по сравнению с подразделениями, таких привилегий не имевшими. В результате неприоритетным сегментам экономики требовался компенсатор, способный заменить дефицитные качественные ресурсы. Дефицит последних в советской экономике обусловил широкое вовлечение в экономический оборот массовых ресурсов. Это явление было названо академиком Ю. В. Яременко «эффектом компенсации». Основной признак компенсирующих процессов - использование в производстве относительно доступной, но несовершенной технологии, требующей больших расходов материалов, электроэнергии, рабочей силы, а также повышенных капитальных вложений.

Как противоположность эффекту компенсации выступает эффект замещения качественными ресурсами массовых, или, вообще говоря, ресурсов более низкого качественного ранга. Данный эффект будет тем выше, чем больше качественный разрыв между взаимодействующими подразделениями. В советской экономике, при относительном избытке массовых ресурсов и больших возможностях использования их компенсирующего влияния, качественные ресурсы практически целиком функционировали в верхних звеньях экономической системы и лишь в незначительных масштабах использовались в целях замещения. При двухуровневой структуре экономики, с одной стороны, существуют предприятия с передовыми технологиями, с другой - производство, основанное на отсталых технологиях или вовсе на ручном труде. Промежуточные уровни, где применяются технологии среднего качества, выражены очень слабо либо отсутствуют совсем. Другими словами, в подобной экономической системе одновременно существуют два технологических уклада.

Интенсивный тип развития экономики, согласно данной концепции, характеризуется следующими признаками:

- возрастает удельный вес средних и верхних хозяйственных уровней и вместе с ними роль процессов замещения; увеличивается глубина замещающих воздействий, исходящих из верхних звеньев;

\footnotetext{
${ }^{1}$ Ввиду складывавшейся в XX в. вокруг СССР военно-политической ситуации к числу таких производств главным образом относились предприятия оборонно-промышленного комплекса. 
13

А. Г. Исаев

№ 32008

• сокращается удельный вес нижних уровней, уменьшается глубина процессов компенсации;

- качественные сдвиги существенно повышают средний технический уровень экономики за счет расширения верхних промежуточных уровней; в нисходящих воздействиях из этих уровней соотношение компенсирующих и замещающих воздействий меняется в пользу последних.

Если брать за основу некий средний качественный уровень производства, то, согласно концепции многоуровневой экономики, интенсивный тип развития экономики наблюдается тогда, когда темпы расширения хозяйственных уровней, находящихся выше качественного центра тяжести системы, превышают темпы расширения слоев, находящихся ниже него. Для экстенсивного типа развития характерен противоположный процесс, связанный с увеличением воздействий компенсационного типа и ростом удельного веса низших хозяйственных уровней.

Ю. В. Яременко рассматривал экономический рост не как количественное увеличение производства, а как «процесс изменения состава ресурсов, их самовоспроизводство с постоянным выделением качественно новых элементов» $[15$, с. 68]. Подобным образом и происходит экономическое развитие передовых стран, задающих траекторию развития мировой экономики.

Таким образом, основой интенсивного экономического роста является увеличение в народном хозяйстве удельного веса таких производственных систем, которые способны генерировать элементы передовых технологических укладов. В свою очередь, эти системы, будучи высокотехнологичными, должны постоянно поддерживать расширение воспроизводственного контура передового технологического уклада путем распространения «замещающих» волн на производства более низкого качественного ранга. В противном случае изолированное развитие высококачественных сегментов будет означать закрепление многоукладности экономики с высоким удельным весом отсталых технологических укладов, при которых экономический рост возможен только экстенсивным способом, т. е. за счет постоянного вовлечения в хозяйственный оборот все большего количества ресурсов.

\section{3. ТЕХНОЛОГИЧЕСКИЙ АСПЕКТ РАЗВИТИЯ ПРОМЫШЛЕННОГО КОМПЛЕКСА ХАБАРОВСКОГО КРАЯ}

Если рассматривать индустриальное развитие Дальнего Востока с точки зрения теории многоуровневой экономики, то можно сказать, что регион изначально являлся источником массовых ресурсов (в основном полезных ископаемых и древесины), и лишь с начала 1930-х гг, когда был установлен приоритет развития отраслей военно-промышленного комплекса, для Дальне- 
го Востока стали централизованно выделяться качественные ресурсы. Однако создание ядра высококачественных ресурсов явилось внеэкономическим решением ${ }^{1}$ и поэтому могло функционировать только при поддержке государства. Развитие отраслей гражданского машиностроения, большая часть которых была размещена в Хабаровском крае также по внеэкономическим мотивам ${ }^{2}$, не являлось для государства приоритетным и поэтому могло рассчитывать лишь на получение ресурсов низкого качества. Но и специфика функционирования высокотехнологичной оборонной промышленности не предполагала прямой передачи высоких технологий отраслям гражданского производства. Таким образом, развитие промышленности края, имеющей в основном утяжеленную структуру из-за преобладания добывающих и машиностроительных предприятий, происходило с упором на компенсационные эффекты, обеспечиваемые определенным сбалансированным соотношением цен.

Уже в 1970-х гг. интенсивность экономического развития в регионе стала снижаться ввиду падения фондоотдачи, и экономический рост поддерживался в основном за счет увеличения физических объемов капитала [6, с. 192] и трудовых ресурсов. О невысоком технологическом уровне гражданского машиностроения говорит и крайне низкая степень технологической сопряженности оборудования, выражающаяся в том, что прогрессивное оборудование (станки с ЧПУ, обрабатывающие центры и т. д.), поставляемое по централизованному распределению, плохо вписывалось в существующую технологическую цепь и в основном оставалось невостребованным. Как следствие, эффективность использования новой техники была низка [3, с. 166]. Вышеуказанные факты говорят о структурно-технологическом неравновесии экономики региона. Поэтому неудивительно, что при смене модели функционирования экономики в начале 1990-х гг. машиностроительная отрасль Хабаровского края оказалась в глубоком кризисе.

Вместо того чтобы стимулировать модернизацию экономики за счет внедрения качественных технологий, либерализация цен привела лишь к вздорожанию массовых ресурсов, что резко снизило возможность экономики нивелировать недостаток качественных ресурсов компенсационными эффектами. При имеющихся технологиях и в условиях резкого возрастания производственных затрат были нарушены условия воспроизводства. Образо-

${ }^{1}$ Главными катализаторами централизованной «накачки» материальными ресурсами Дальнего Востока послужили обострения внешней военно-политической обстановки на тихоокеанском рубеже в 1920-х и 1960-х гг.

${ }^{2}$ Из соображений безопасности государству необходимо было принять меры, препятствующие попыткам парализовать промышленное производство со стороны потенциальных стран-агрессоров. В условиях постоянного ожидания военных угроз извне остро стояла необходимость дублирования производств путем размещения их в максимально удаленных друг от друга районах страны. 
вавшиеся неиспользуемые ресурсы привели к росту безработицы, падению загрузки производственных мощностей и, как следствие, значительному сокращению объемов производства в обрабатывающем секторе экономики Хабаровского края.

В качестве оценки динамики технологического развития промышленности Хабаровского края в статье использована динамика совокупной факторной производительности (СФП), полученная с помощью производственной функции Р. Солоу [20] вида:

$$
\frac{\Delta y}{y}=\frac{\Delta A}{A}+\alpha \frac{\Delta k}{k}
$$

откуда

$$
\begin{gathered}
\frac{\Delta A}{A}=\frac{\Delta y}{y}-\alpha \frac{\Delta k}{k}, \\
\mathrm{~A}_{t+1}=A_{t}+\frac{\Delta A}{A_{t}},
\end{gathered}
$$

где $\Delta y / y$ - годовой темп роста ВДС на одного занятого; $\Delta A / A$ - годовой прирост СФП; $\Delta k / k$ - годовой темп роста физического объема основных фондов на одного занятого; $\alpha$ - цена фактора производства - капитала, рассчитанная в данном случае как единица минус удельный вес затрат на оплату труда работников в общем объеме ВДС. Динамика $A_{t}$ за период 1980-1989 гг., рассчитанная по активной части основного капитала (без учета зданий и сооружений) промышленности Хабаровского края, показана на рисунке 1.

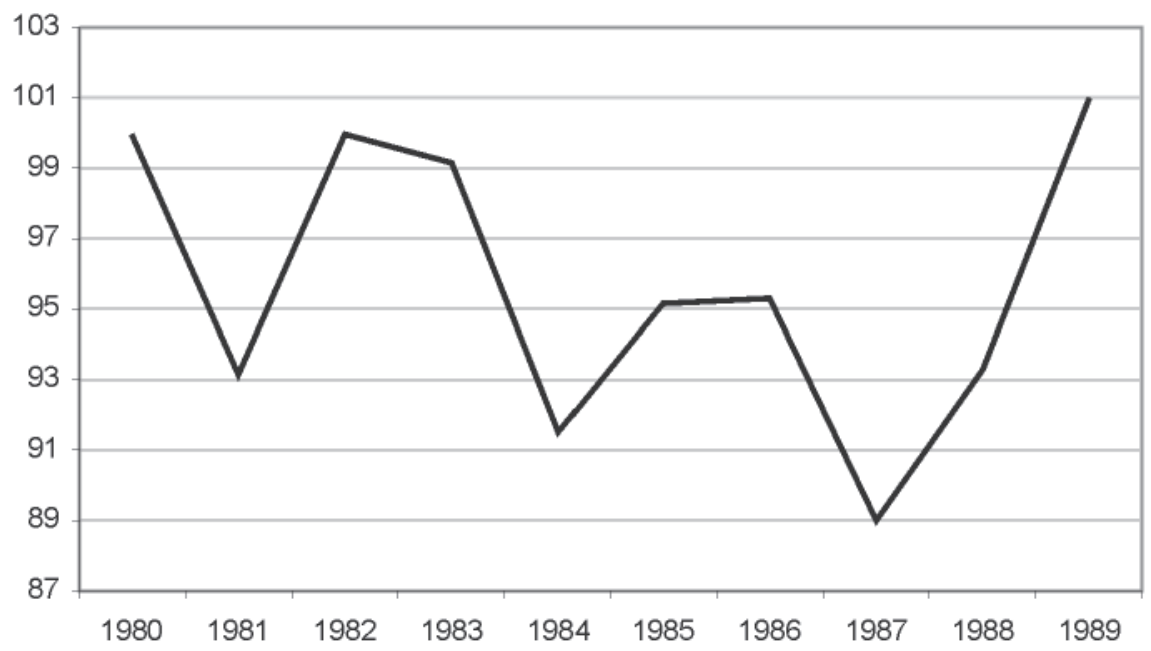

Puc. 1. Динамика совокупной факторной производительности для промышленности Хабаровского края за период 1980-1989 гг., \% к 1980 г. 
Как видно из рисунка 1, уже в 1980-х гг. в Хабаровском крае не наблюдалось повышения технологического уровня промышленного производства, но в то же время отмечался рост физического объема основного капитала и численности занятых в промышленности ${ }^{1}$. Это говорит о том, что прирост объемов промышленного производства достигался в основном за счет дополнительного вовлечения в хозяйственный оборот массовых ресурсов. Вполне естественно, что и в 1990-х гг., в отсутствие масштабной реорганизации вторичного сектора экономики, повышения общего технологического уровня промышленности произойти не могло, как это и следует из рисунка $2^{2}$.

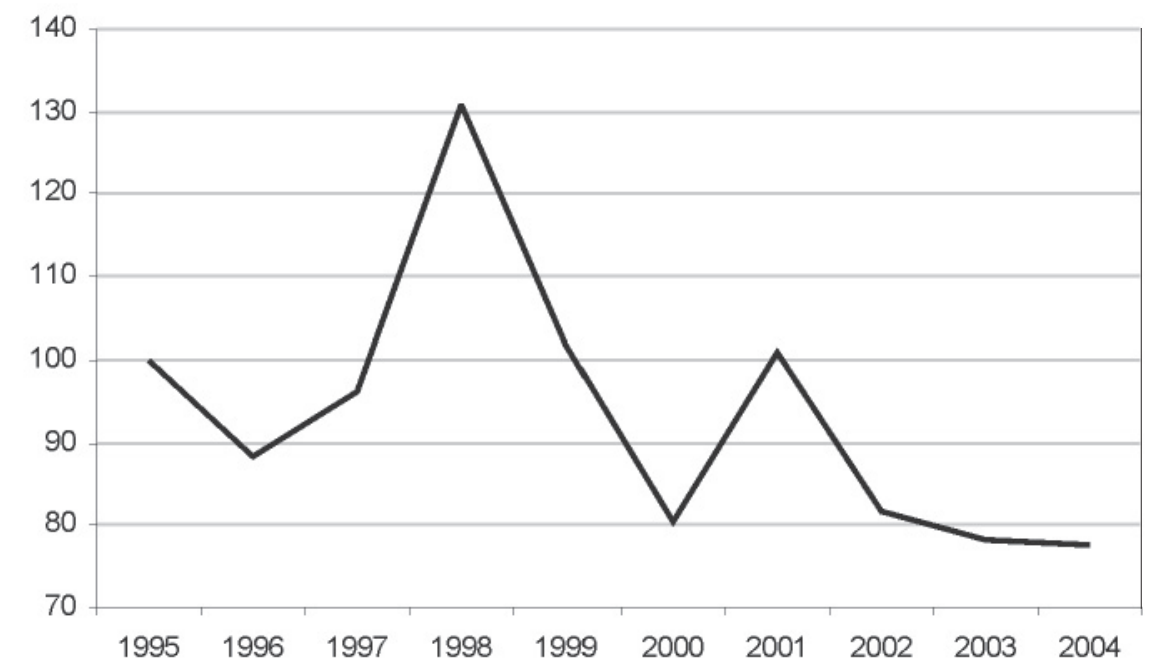

Puc.2. Динамика совокупной факторной производительности для промышленности Хабаровского края за период 1995-2004 гг., \% к 1995 г.

Значительная часть послекризисного (с 1998 г.) роста объемов промышленного производства обеспечивалась главным образом за счет высокотехнологичного сектора обрабатывающей промышленности, динамика которого в большей степени зависела от наличия государственных оборонных заказов. Кроме того, ориентация оборонного сектора на внешний спрос указывает на его определенную экономическую обособленность и слабую связь с внутренним региональным рынком (если рассматривать такую связь в виде потенциальных процессов замещения).

Кризис, поразивший промышленный комплекс Хабаровского края, не в

${ }^{1}$ С 1980 по 1987 г. численность промышленных рабочих увеличилась на 10\%, объем основных фондов - в 1,7 раза.

2 При расчете СФП для периода 1995-2004 гг. вместо основных фондов использовались инвестиции в основной капитал промышленности на одного занятого. 
последнюю очередь связан с низким качеством технологий, которыми были оснащены предприятия добывающего и обрабатывающего секторов, и прежде всего - гражданского машиностроения. Отрасль, созданная по внеэкономическим критериям и поддерживаемая финансовыми и материальными ресурсами из центра, оказалась неспособной функционировать после введения экономических критериев. Кроме того, по причине жесткого контроля над использованием высоких технологий в весьма узком сегменте производства соотношение массовых и качественных ресурсов сложилось в регионе исторически не в пользу последних и продолжает оставаться практически неизменным по настоящее время.

Характерной особенностью промышленного комплекса Хабаровского края является присутствие в нем производств пятого (главным образом - авиационная промышленность) и четвертого (нефтепереработка, черная металлургия) технологических укладов. Однако средний качественный уровень экономики Хабаровского края достаточно низок, основная масса производств лежит в области низких технологий. Ввиду слабой инвестиционной активности предприятий гражданского машиностроения этот уровень продолжает снижаться. Продолжающееся движение вниз по шкале отдачи ресурсов ставит под угрозу перспективы повышения эффективности функционирования регионального комплекса обрабатывающих производств.

Ухудшение среднего качественного уровня экономики региона не перекрывается расширением высшего технологического уклада. КнААПО, став подразделением холдинга «Сухой» и включившись в производство нового регионального пассажирского самолета Superjet 100, благодаря крупным капиталовложениям в передовые технологии значительно расширило свою производственную базу, а вместе с тем и удельный вес пятого технологического уклада в регионе. Однако этот «островок» высоких технологий на Дальнем Востоке остается практически не интегрированным в региональные производственные связи. Будучи подразделением холдинга, предприятие не участвует в каких-либо производственных цепочках на территории Хабаровского края, а следовательно, не является источником замещающих волн на нижние уровни технологической иерархии региона и в рыночных условиях хозяйствования. В рамках производственной системы Хабаровского края КнААПО, по сути, автономный, экстерриториальный экономический агент.

При таком положении дел интенсивный путь развития экономики региона (если понимать под таковым повышение эффективности используемых в производстве технологий) представляется маловероятным. Промышленный комплекс Хабаровского края, испытывая постепенное ухудшение среднего уровня качества используемых ресурсов, отсутствие в значительном объеме капиталовложений в передовые технологии, рискует в будущем деградиро- 
вать вплоть до вырождения до уровня узколокальных производств. Данная ситуация совершенно не вписывается ни в один сценарий развития Дальнего Востока, как с позиций роли и места, отводимых региону в стратегии социально-экономического развития страны, так и с позиции места России в мировой экономике. Следовательно, один из главных путей решения существующей проблемы - повышение качества используемых в промышленности ресурсов.

\section{4. ВОЗМОЖНЫЕ ПУТИ РЕШЕНИЯ ТЕХНОЛОГИЧЕСКИХ ПРОБЛЕМ ПРОМЫШЛЕННОСТИ ХАБАРОВСКОГО КРАЯ}

Можно выделить две принципиально различные схемы усложнения общего технологического уровня промышленности региона: усложнение «снизу» и усложнение «сверху». Первая из них состоит в повышении среднего качественного уровня системы путем замены массовых ресурсов нижнего уровня на более качественные факторы производства (т. е. путем инвестиций в основной капитал уже существующих, рыночно востребованных предприятий) или создание условий для возникновения в регионе принципиально новых технологических комплексов. Вторая схема заключается в том, чтобы привести в действие механизмы передачи технологических импульсов от высших технологических укладов к более низким, т. е. в реализации полноценного эффекта замещения.

Среди предприятий обрабатывающей промышленности региона за последнее десятилетие благодаря крупномасштабным инвестициям повышают свой технологический уровень предприятия черной металлургии и нефтеперерабатывающей промышленности. Первая отрасль, имея удобное географическое положение по отношению к основным зарубежным рынкам сбыта продукции (страны Азиатско-Тихоокеанского региона), наращивает свои конкурентные преимущества за счет увеличения ассортимента выпускаемой продукции. Вторая отрасль имеет достаточно емкий внутренний рынок. Примеры высокотехнологичных производств в гражданском машиностроении региона довольно немногочисленны, однако определенные точки качественного роста можно выделить и здесь. Так, предприятие «Дальреммаш», специализирующееся на производстве технологического оборудования для рыбоперерабатывающей и пищевой промышленности, благодаря своевременному внедрению новых технологий смогло стать конкурентоспособным на современном рынке. Условием внутренней генерации качественных ресурсов здесь выступает тесное взаимодействие в целях внедрения передовых технологий как с дальневосточными научно-исследовательскими учреждениями (ТИНРО-центр, Дальрыбвтуз), так и с научными организациями запад- 
ных районов страны («БалттехмашПроект», Атлантический НИИ рыбного хозяйства). В результате увеличения ассортимента выпускаемой конкурентоспособной продукции, география сбыта на сегодняшний день простирается и за пределы Дальнего Востока. Это характерный пример эффективной адаптации машиностроительного производства под нужды одной из основных отраслей специализации Дальнего Востока (рыбная промышленность), о необходимости которой в самом удаленном регионе страны высказывались ученые еще в 1980-х гг.

Другим способом усложнения технологической структуры «снизу» является создание условий в крае для размещения новых технологических комплексов. Одним из самых крупных проектов в этом направлении можно назвать строительство алюминиевого завода норвежской компанией Hydro Aluminium, который может стать одним из потребителей электроэнергии строящихся дальневосточных ГЭС. Другим фактором, говорящим в пользу строительства завода, является развивающаяся инфраструктура доставки сырья и готовой продукции от морских портов Хабаровского края до места дислокации будущего завода.

Наиболее желаемым способом усложнения технологической структуры экономики региона, принимая во внимание наличие на его территории наукоемких производств пятого технологического уклада, является организация процесса передачи технологических импульсов от производств высшего уклада к более низким уровням, т. е. активизация процессов замещения. Однако, учитывая практически полное отсутствие подобных взаимосвязей производств разных технологических укладов в регионе, данный способ представляется и наиболее сложным. Тем не менее такая возможность существует, и связана она с организацией производства на КнААПО российского регионального пассажирского самолета Superjet 100. Возможность эта заключается в создании на базе данного предприятия аэрокосмического кластера.

Прежде всего необходимо рассмотреть, как функционирует современная мировая авиационная индустрия. Схематично организацию данной отрасли можно представить в виде трехъярусной пирамиды [19]. На ее вершине (первый ярус) находятся основные сборщики самолетов (генеральные подрядчики), такие как Boeing, Airbus, Bombardier, Embraer. Эти промышленные гиганты занимаются разработкой новых моделей самолетов, определением перспективных рынков сбыта и заказом сборочных узлов у поставщиков, образующих второй ярус пирамиды. На этом уровне находятся производители силовых агрегатов, авионики, стоек шасси, гидравлических систем. Сюда же относятся и производители различных конструкций планера самолета. На третьем ярусе сосредоточены производители электронных подсистем, частей 
фюзеляжа, которые представлены на глобальном рынке также относительно небольшим количеством фирм. Помимо этого существует еще одна группа производителей, которую также следует добавить к пирамиде. В различных аэрокосмических кластерах находятся десятки и сотни мелких и средних фирм, поставляющих детали и услуги для производителей второго и третьего ярусов, а в ряде случаев и для головных предприятий первого яруса. Эти предприятия четвертого яруса далеко не всегда полностью специализируются на авиационной промышленности, а предлагают свою продукцию и услуги большому числу других отраслей.

Большинство крупных аэрокосмических кластеров состоят из одного или нескольких крупных производителей авиационной техники и множества мелких и средних производителей частей и компонентов. Существуют кластеры по сборке гражданских самолетов (Монреаль, Сиэтл, Тулуза и др.), кластеры по сборке авиационных двигателей (например, вокруг заводов General Electrics в штатах Огайо и Массачусетс). Переток знаний в виде технологий от крупных производителей к их более мелким поставщикам опосредуется через управление цепочками поставок между этими двумя типами контрагентов. Управление поставками, которое является основной движущей силой распространения технологий в данной отрасли, включает в себя такие сферы деятельности, как технические условия, параллельное проектирование, стратегические проектные альянсы, контроль качества, совместная разработка продукта, сертификация поставщиков, сроки доставки, разделение рисков и затрат, объемы и стоимость продукции [19]. Технологический уровень фирм первого, второго и третьего ярусов достаточно близок, и для них характерны частые и масштабные инвестиции в специфические активы. Фирмы, находящиеся на нижнем ярусе производственной иерархии данной отрасли, как правило, технологически отдалены от своего основного потребителя и лишь изредка инвестируют в специфические активы, в том числе и потому, что не зациклены полностью на одной отрасли [18].

Внутри иерархической пирамиды для осуществления производственного процесса определенным образом организованы материальные и информационные потоки, которые можно разделить на три основные группы.

1. Поток «сверху вниз», включающий в себя материалы для переработки и сборки, информацию и технологии. Исходя от фирм-лидеров, он проходит через всю пирамиду вплоть до субподрядчиков нижних ярусов. Данный поток имеет своей целью координацию деятельности и распространение технологий среди всех фирм-участников (посредством разработки дизайна, спецификации компонентов, информации о сроках и затратах и т. д.).

2. Поток «снизу вверх» включает уже изготовленные части, компоненты, а также необходимую информацию по производственным процессам. 
3. Горизонтальные потоки, осуществляющиеся между фирмами, работающими одновременно над различными частями одной программы. Они включают в себя необходимые связи между различными элементами авиалайнера, технологии, компоненты и требуемую информацию о технических характеристиках изделия.

КнААПО выбрано одним из двух головных изготовителей (наряду с новосибирским НАПО) самолета Superjet 100, который создается в рамках широкой международной кооперации с использованием накопленного производственного потенциала мировых фирм-производителей. Принимая во внимание то, что окончательная сборка самолета производится в г. Комсомольске-на-Амуре, можно представить КнААПО основным головным производителем, т. е. фирмой первого яруса, согласно приведенной выше схеме. Второй ярус образуют поставщики частей фюзеляжа (НАПО), двигателя (Snecma) и авионики (Thales). Третий ярус представлен производителями таких агрегатов, как системы управления самолетом (Liebherr Aerospace), гидравлическая система (Parker), шасси (Messier-Dowty), вспомогательная силовая установка (Honeywell), аварийное оборудование (Air Cruise), двери и элементы интерьера (В/E Aerospace) и др. Кроме того, в рамках производства осуществляется кооперация с Воронежским акционерным самолетостроительным обществом (ВАСО), где организовано высокотехнологичное производство деталей и изделий из полимерных композиционных материалов (15\% стоимости самолета), а также деталей, предназначающихся для стыковки планера и окончательной сборки самолета [5]. Между тем, мелких и средних предприятий четвертого яруса, которые могли бы непосредственно в Хабаровском крае стать основой аэрокосмического кластера, участвуя в тесной кооперации с фирмами вышестоящих ярусов и тем самым поднимая экономику региона вверх по технологической шкале, не существует. В связи с этим полезно обратиться к опыту по организации подобного кластера вокруг производственных мощностей бразильского авиаконцерна Embraer, занимающегося производством региональных пассажирских реактивных самолетов аналогичного с Superjet 100 класса, т. е. являющегося одним из основных конкурентов российского производителя на глобальном рынке.

На сегодняшний день порядка 40 локальных малых и средних предприятий, оказывающих компании Embraer производственные услуги (инжиниринг, программное обеспечение, термическая обработка деталей самолета и т. д.), а также поставляющих авиационную электронику и другие компоненты, образуют авиапромышленный кластер, расположенный в окрестностях г. Сан-Жозе-дус-Кампус (штат Сан-Паулу). Большинство из местных поставщиков были созданы бывшими сотрудниками компании Embraer под еe непосредственным патронажем. Эти предприятия тесно взаимодействуют с 
местными центрами НИОКР и участвуют в производственной цепочке посредством прямых субконтрактов с Embraer. Кроме того, на территории кластера расположены другие фирмы, включенные в производственный процесс через систему субконтрактов с основными зарубежными партнерами авиаконцерна. Некоторые предприятия, поставляющие детали и оказывающие технические услуги, расположены в других регионах Бразилии. Все эти высококонкурентные фирмы были созданы не рыночными силами, а явились следствием реализации целенаправленной промышленной политики.

Развитию местного аэрокосмического кластера способствовал ряд инфраструктурных преимуществ. Территория г. Сан-Жозе-дус-Кампус имеет развитую логистику благодаря стратегическому расположению города возле скоростной автотрассы, соединяющей два главных деловых центра Южной Америки. Также в распоряжении предприятий, расположенных вдоль магистрали, имеются газовый трубопровод и оптоволоконная сеть. Более того, в относительной близости расположены морские порты в городах Сан-Себастьян и Сантос. Модернизация местного аэропорта, позволившая принимать международные грузовые рейсы, также явилась серьезным вкладом в развитие региона.

Успешное функционирование аэрокосмического кластера в Бразилии во многом результат действий правительства по созданию в регионе научной и образовательной инфраструктуры в целях соответствия высоким требованиям отрасли. В частности, были созданы Национальный институт космических исследований и Технологический аэрокосмический центр, состоящий из четырех институтов образовательного и исследовательского характера [17]. В 1992 г. с целью стимулирования создания наукоемких малых и средних предприятий был образован специальный фонд Pylo Vale Foundation. B 1997 г. местным муниципалитетом был образован Секретариат экономического развития с целью стимулирования местного развития и привлечения инвестиций. Совместно с Embraer был разработан план организации авиапромышленного комплекса на территории 200 тыс. м². Также был разработан совместный проект экспортного консорциума, куда привлекались мелкие и средние предприятия-поставщики частей и компонентов для Embraer. Главной целью консорциума являлось поощрение экспорта через снижение фиксированных затрат предприятий и увеличение локального производства комплектующих. Статус поставщиков товаров и услуг для Embraer позволяет местным компаниям оказывать аналогичные услуги и для зарубежных партнеров авиаконцерна.

Местные производители получают от головной компании сырье, полуфабрикаты, чертежи и поставляют обратно готовую продукцию или услуги. Кооперация между компаниями осуществляется посредством процессов обу- 
чения, в целях достижения требуемого качества продукции и услуг. Embraer осуществляет обучение персонала малых предприятий, их технический мониторинг, а также процесс передачи технического опыта с помощью собственных инженеров, распространяющих соответствующие знания [16].

Что касается перспектив развития аэрокосмического кластера в Хабаровском крае, то многие предпосылки, повлиявшие на успех бразильского производителя, существуют и здесь. Прежде всего, это созданный научный потенциал в данной области. Аккумуляция новых знаний и опыта на головном предприятии облегчается и тем, что КнААПО является подразделением холдинга «Сухой», имеющего собственную мощную научно-исследовательскую базу, формировавшуюся на протяжении десятилетий. Помимо этого на территории края расположены предприятия и организации, имеющие значительный опыт постройки сложных объектов и сооружений: проектные и строительные организации, предприятия по изготовлению и монтажу промышленного, технологического и коммунального оборудования, металлических конструкций, изготовлению кабельной продукции, сооружению средств связи и оказанию телекоммуникационных услуг. Другим благоприятным фактором является развивающаяся транспортная инфраструктура Хабаровского края (автомобильные и железные дороги, магистральный газопровод, морские порты и аэропорты). Кроме того, будущее строительство алюминиевого завода также может внести значительный вклад в развитие потенциального аэрокосмического кластера ${ }^{1}$. Эти условия вполне могут являться основанием для организации на территории края мелких и средних производств, способных повысить в перспективе долю частей и компонентов, производимых на месте и с меньшими издержками. Такова наиболее реальная схема, позволяющая активизировать процессы распространения высоких технологий на нижние слои технологической структуры региона и тем самым продвигаться по пути ее постепенного усложнения.

\section{5. ЗАКЛЮЧЕНИЕ}

В данной статье были рассмотрены некоторые фундаментальные препятствия для выведения экономики Хабаровского края на траекторию устойчивого роста. Показана невозможность созданного промышленного комплекса выступать в качестве источника генерации новых технологических импульсов, жизненно необходимых для активизации процессов интенсивного развития производственной базы региона.

1 Несмотря на то, что в самолетостроении активно внедряется использование композиционных материалов, содержание алюминия в современном самолете составляет не менее $60 \%$ от его общего веса. 
Повышение общего технологического уровня возможно путем внедрения в существующие предприятия новых технологий взамен устаревших путем создания совершенно новых, рыночно востребованных производств, а также с помощью активизации эффекта замещения, т. е. создания условий, при которых производства высших технологических укладов передают современные технологии (в виде разработок и специальных знаний) производствам низших укладов.

Первые два типа повышения технологического уровня в разной мере присутствуют на территории региона. Они постепенно повышают средний технологический уровень промышленности, однако совсем не очевидно, что этим самым придается импульс генерации новых технологических укладов. Поскольку происходит лишь внедрение более совершенных технологий (в виде основного капитала), но не новых знаний, специфического производственного опыта и инфраструктуры, способствующей их распространению. Существующие исключения (например, завод «Дальреммаш») немногочисленны. Совершенно иные по своей значимости последствия могут возникнуть при третьем способе повышения среднего технологического уровня системы. Здесь уже передача технологий посредством управления цепочками поставок происходит наряду с генерацией и передачей новых знаний и производственных наработок. Такая схема трансферта технологий уже активизирует процессы возникновения и расширения нововведений на любых уровнях технологической иерархии производственной системы. Именно она представляется наиболее актуальной в деле постановки промышленного комплекса Хабаровского края на рельсы инновационного развития, о котором в последние годы ведется речь на всех уровнях государственной власти. И несмотря на то, что имеются все предпосылки для осуществления в регионе подобного сценария, он реализуем только при соответствующем содействии федеральных и региональных властей по организации и развитию локальной инновационной среды в авиапромышленной отрасли, по созданию институтов, способствующих появлению малых и средних высокотехнологичных фирм вокруг головного предприятия и обеспечивающих их взаимодействие с динамично развивающимися источниками специальных научных знаний. В конечном счете, опыт компании Embraer и бразильского правительства по организации кооперационных связей, способствующих динамичному развитию столь сложной отрасли, является ярким примером успешной организации каналов передачи научных знаний в локальной производственной среде и, несомненно, должен быть учтен при подобных начинаниях и в Хабаровском крае. 


\section{СПИСОК ЛИТЕРАТУРЫ}

1. Глазьев С. Ю. Экономическая теория технического развития. М.: Наука, 1990.

2. Глазьев С. Ю. Развитие российской экономики в условиях глобальных технологических сдвигов. Научный доклад. http://www.glazev.ru/files/doklad_22marta.zip

3. Дальний Восток России: экономический потенциал. Владивосток: Дальнаука, 1999.

4. Кондратьев Н. Д. Большие циклы конъюнктуры и теория предвидения. Избранные труды / Н. Д. Кондратьев; Международный фонд Н. Д. Кондратьева и др.; Ред. колл.: Абалкин Л. И. (пред.) и др.; сост. Яковец Ю. В. М.: ЗАО «Издательство «Экономика», 2002.

5. Маценов Д. В. Производство самолетов Superjet-100: создание высокотехнологичного производства на Дальнем Востоке и в Сибири. Доклад на Дальневосточном международном экономическом форуме. Хабаровск, 2006. http://www.dvforum. ru/2006/doklads/dokl_T6_Macenov.aspx

6. Минакир П. А. Экономическое развитие региона: программный подход. М.: Наука, 1983.

7. Обучение рынку / Под ред. С. Ю. Глазьева. М.: ЗАО «Изд-во «Экономика», 2004.

8. Промышленность Хабаровского края в 1984 г.: Стат. сб. / ЦСУ РСФСР. Статистическое управление Хабаровского края. Хабаровск, 1985.

9. Промышленность Хабаровского края в 1990 г.: Стат. сб. / Госкомстат РСФСР. Хабаровское краевое управление статистики. Хабаровск, 1991.

10. Регионы России: Стат. сб. В 2 т. Т. 2 / Госкомстат России. М., 1999.

11. Регионы России: Стат. сб. В 2 т. Т. 2 / Госкомстат России. М., 2001.

12. Регионы России. Социально-экономические показатели. 2003: Стат. сб. / Госкомстат России. М., 2003.

13. Регионы России. Социально-экономические показатели. 2005: Стат. сб. / Росстат. М., 2005.

14. Узяков M. Н. Взаимодействие качественных и массовых ресурсов и эффективность экономики // Проблемы прогнозирования. 2001. № 1.

15. Яременко Ю. В. Теория и методология исследования многоуровневой экономики. М.: Наука, 1997.

16. Bernardes $R$. Passive innovation system and Local Learning: A Case Study of Embraer in Brazil. Materials of The First Globelics Conference of Innovation Systems and Development Strategies for the Third Millinium'. Rio de Janeiro, 2003. http://redesist. ie.ufrj.br/globelics/pdfs/GLOBELICS_0082_Bernardes.pdf

17. Cassiolato J., Bernardes R., Lastres H. Transfer of Technology for Successful Integration into the Global Economy. A Case Study of Embraer in Brazil. (UNCTAD/UNDP, 2002). http://www.unctad.org/en/docs/iteipcmisc20_en.pdf.

18. Esposito E., Passaro R. Logistics and Organisational Changes: The Effect on Customer-Supplier Relationships // International Journal of Logistics, Research and Applications. 1998. Vol. 1. № 2.

19. Niosi J., Zhegu M. Aerospace Clusters: Local or Global Knowledge Spillovers? // Industry and Innovation, Vol. 12. № 1. 2005.

20. Solow R. Technical Change and the Aggregate Production Function // The Review of Economics and Statistics. Vol. 39. № 3. 1957. 